\title{
Amelioration of polycystic ovary syndrome- related disorders by supplementation of thymoquinone and metformin
}

\author{
Islam Mohamed Magdi Ammar* (iD and Mostafa Abdo Ahmed Salem
}

\begin{abstract}
Background: Polycystic ovary syndrome (PCOS) is one of the most common endocrine disorders of reproductive age women with a prevalence of $4-12 \%$. The study aimed to investigate the potential benefit of adding thymoquinone to metformin in alleviating symptoms of polycystic ovarian syndrome. Two hundred seven overweight and obese PCOS patients were divided into two groups. Patients in group A received metformin 500 $\mathrm{mg}$ three times daily for 6 months. Patients in group B received a combination of metformin $500 \mathrm{mg}$ and thymoquinone in the form of black cumin oil $500 \mathrm{mg}$ capsules three times daily for 6 months. Follow-up was done after 3 and 6 months from the beginning of the study for evaluation of menstrual cycle pattern, body mass index, waist circumference, hip circumference, and waist:hip ratio, oral glucose tolerance test, glycosylated hemoglobin A1C, superoxide dismutase activity, and malondialdehyde concentration.

Results: Patients who received a combination of black cumin oil capsules and metformin, showed a significant decrease in number of patients suffering from amenorrhea or oligomenorrhea $(P=0.031)$, significant $(P=0.00)$ weight reduction (reduced $\mathrm{BMI}$ ), and body fat redistribution (reduced $\mathrm{W} / \mathrm{H}$ ratio), regaining oxidative balance with significant increase of SOD activity $(P=0.00)$ and decrease of MDA concentrations $(P=0.03)$. Regarding the number of prediabetic patients, there was no statistically significant difference $(P=0.89)$ when both groups were compared at the end of study period.

Conclusions: Black cumin oil supplementation constitutes a beneficial added value to metformin in ameliorating PCOS-related disorders with resumption of menstrual regularity, weight reduction, change of body fat distribution, and regaining oxidative balance.
\end{abstract}

Keywords: Thymoquinone, Black cumin oil, Metformin, PCOS

\section{Background}

Polycystic ovary syndrome (PCOS) represents the most common endocrine disorder affecting $7 \%$ of females in the reproductive age [1]. The estimated cost of diagnosis and treatment in the USA is more than 4 billion dollars per year. PCOS patients are subjected to an increased risk of type 2 diabetes mellitus (DM) and almost one-

\footnotetext{
* Correspondence: islamammar146@gmail.com

Department of Obstetrics and Gynecology, Faculty of Medicine, Zagazig University, Zagazig City, Sharkia, Egypt
}

third of PCOS patients suffer from impaired glucose tolerance [2].

Oxidative stress has been implicated in the pathogenesis of the disorder and hence the role of antioxidants in management of PCOS. The use of antioxidants has been reported to improve the rate of ovulation and glycemic control in PCOS patients [3, 4].

Insulin sensitizers have been used for reversal of PCOS-related clinical and metabolic manifestations based on the link between insulin resistance and the pathogenesis of the disorder. Over the past 50 years, metformin has been used as the most common sensitizer

\section{Springer Open}

(c) The Author(s). 2021 Open Access This article is licensed under a Creative Commons Attribution 4.0 International License, which permits use, sharing, adaptation, distribution and reproduction in any medium or format, as long as you give appropriate credit to the original author(s) and the source, provide a link to the Creative Commons licence, and indicate if changes were made. The images or other third party material in this article are included in the article's Creative Commons licence, unless indicated otherwise in a credit line to the material. If material is not included in the article's Creative Commons licence and your intended use is not permitted by statutory regulation or exceeds the permitted use, you will need to obtain permission directly from the copyright holder. To view a copy of this licence, visit http://creativecommons.org/licenses/by/4.0/. 
of insulin in patients with type 2 diabetes and in nondiabetic ladies with PCOS with an evidence of both: reproductive and metabolic advantages, especially restoration of regular cycles and normal ovulation [5].

Nigella sativa (NS) is a member of the Ranunculaceae botanical family (also called black seed, black cumin). It has been used in the Middle and Far East for more than 2000 years as a traditional remedy in the form of seeds and oil to treat various diseases like diabetes, asthma, rheumatoid, and other related inflammatory diseases. Thymoquinone (2-isopropyl-5-methylbenzo-1, 4quinone) (TQ) is the biologically active component of the NS seeds, and hence most of the known actions of NS have been attributed to it [6].

El-Dakhakhny was the first to extract TQ in 1963 by using thin layer chromatography on silica gel $[7,8]$. TQ is present in two forms: the enol and the keto forms. The keto form is responsible for the pharmacological properties and represents the major fraction (almost 90\%) [9].

TQ is a hydrophobic molecule, and hence its solubility represented a challenge for its bioavailability and caused much of the limitations in drug formulation [10]. When administered orally, the liver enzyme (quinine reductase) transforms it into hydroquinone. Thus, TQ represented a compound with rapid elimination and relatively slow absorption after oral administration [6].

The use of natural antioxidants and phytochemicals has gained increased interest in treatment of oxidative stressrelated diseases due to their abilities to quench free radicals [9]. Reactive oxygen species (ROS) are continuously generated in the cells by aerobic metabolism and in response to exposure to environmental pollution and ultraviolet radiation. Generation of ROS leads to oxidization of membrane lipids, proteins, and nucleic acids. Antioxidant enzymes such as superoxide dismutase (SOD), glutathione (GSH), catalase (CAT), glutathione peroxidase (GSH-Px), and glutathione-S-transferase (GST) represent an essential part of the cellular defense mechanism against ROS [6]. TQ is considered a potent phytochemical antioxidant due to its ability to scavenge several ROS and thus antagonizes the effects of elevated levels of ROS in various diseases [11]. TQ reacts with glutathione (GSH), NADH, and NADPH to form reduced metabolites, such as glutathionyl-dihydro$\mathrm{TQ}$, that can remove free radicals [12].

TQ exerts anti-diabetic activity through enhancing glucose utilization, decreasing the hepatic glucose production (by decreasing the activity of the gluconeogenic enzymes), and preserving the pancreatic beta-cell integrity (by decreasing Malondialdehyde (MDA) levels, along with increasing SOD levels in the pancreatic tissue) $[13,14]$.

\section{Aim of the study}

This study aimed to investigate the potential benefit of adding the biologically active component of Nigella sativa oil (thymoquinone) to metformin in alleviating symptoms of polycystic ovarian syndrome.

\section{Methods}

This randomized clinical trial was conducted in the Department of Obstetrics and Gynecology at the Saudi German Hospital, Madinah, KSA, during the period from February 2019 to August 2020. The study included 207 patients who fulfilled the following inclusion criteria: age of 18 to 35 years, overweight and obese PCOS patients (overweight defined as body mass index (BMI) 25$29.9 \mathrm{~kg} / \mathrm{m}^{2}$ and obesity defined as BMI $\geq 30 \mathrm{~kg} / \mathrm{m}^{2}$ ) attending the outpatient clinic, and complaining of amenorrhea or oligomenorrhea with or without hirsutism. Amenorrhea was defined as absence of menstruation for 6 or more months. Oligomenorrhea was defined as cycle interval of more than 35 days but less than 6 months. PCOS was diagnosed according to the 2004 Rotterdam ESHRE/ASRM Consensus workshop [15], with presence of at least 2 out of 3 criteria: oligo- and/or anovulation, clinical and/or biochemical hyperandrogenism, and polycystic ovarian morphology identified by ultrasound with more than 12 small antral follicles in an ovary, with exclusion of other related etiologies like androgensecreting tumors, congenital adrenal hyperplasia, and hyperprolactinemia. Prediabetes patients who are at increased risk of developing diabetes, as defined by the American Diabetes Association 2014 [16], were included. Those patients had impaired fasting glucose (IFG) defined as fasting plasma glucose (FPG) levels of 100 to $125 \mathrm{mg} / \mathrm{dL}$ (fasting was described as no caloric intake for at least $8 \mathrm{~h}$ ), or impaired glucose tolerance (IGT) defined as 2-h readings of 140 to $199 \mathrm{mg} / \mathrm{dL}$ in the oral glucose tolerance test (OGTT). Patients who were considered at very high risk of developing diabetes according to the International Expert Committee 2009 [17] were also included. Those patients had their glycosylated hemoglobin A1C levels between 5.7 and 6.4\%.

Exclusion criteria were as follows: lean or average weight PCOS with BMI $<25 \mathrm{~kg} / \mathrm{m}^{2}$, morbidly obese patients with BMI $\geq 35 \mathrm{~kg} / \mathrm{m}^{2}$, patients suffering from any other metabolic disorders, history of receiving any hormonal treatment or any drug affecting carbohydrate metabolism 3 months prior to the beginning of the study, and inability to attend the regular follow-up visits. Already known and recently diagnosed diabetic patients were excluded from the study. According to the American Diabetes Association 2014 [16], diabetes mellitus was defined as glycosylated hemoglobin A1C levels $\geq$ $6.5 \%$ or FPG $\geq 126 \mathrm{mg} / \mathrm{dL}$ or 2 -h plasma glucose readings $\geq 200 \mathrm{mg} / \mathrm{dL}$ during $75 \mathrm{~g}$ OGTT, or presence of classic symptoms of hyperglycemia with random plasma glucose levels $\geq 200 \mathrm{mg} / \mathrm{dL}$. Thyroid diseases and hyperprolactinemia were treated before participation. 
The study was in accordance with the Helsinki Declaration 1964 and its later amendments. The study protocol was approved by the local ethics committee. All patients signed an informed consent before participation.

During the first booking visit, initial assessment was carried out with detailed history taking, including personal, medical, surgical, obstetric, and menstrual history. General examination was done with measurement of BMI, waist circumference (WC), hip circumference (HC), and waist:hip ratio (WHR).

BMI had the disadvantage of not truly representing the body fat distribution and hence the nature of obesity as concluded by many studies. So, the waist circumference, hip circumference, and waist:hip ratio were selected as more convenient measures of abdominal visceral fat and hence important clinical markers to predict patients at risk of developing DM and cardiovascular diseases [18].

Measurements were carried out according to the World Health Organization (WHO) STEPS protocol 2008. Waist circumference was measured at the midpoint between the lower margin of the last palpable rib and the top of the iliac crest. Hip circumference was measured around the widest portion of the buttocks. For both measurements, the tape was adjusted parallel to the floor at the level at which the measurement was made. The tape was held snugly around the body, but not pulled so tight. The patient was standing with feet close together, arms at the sides, and body weight evenly distributed across the feet. The waist circumference was measured at the end of a normal expiration, when the lungs are at their functional residual capacity. Because many individuals unconsciously react to waist measurements by sucking their abdominal wall, the patients were advised to relax and take a few natural breaths before the actual measurement was made. Each measurement was repeated twice; if the measurements were within 1 $\mathrm{cm}$ of one another, the average was calculated. If the difference between the two measurements exceeded $1 \mathrm{~cm}$, the two measurements were repeated $[15,19]$.

During the booking visit, a basal pelvic ultrasound was done for virgin participants and transvaginal ultrasound (TVS) for non-virgin patients. Blood samples were also collected for OGTT, glycosylated hemoglobin A1C levels, estimation of SOD activity, and MDA concentrations.

The oral glucose tolerance test (OGTT) was performed in the morning after an overnight fasting of at least $8 \mathrm{~h}$, utilizing a glucose load containing the equivalent of $75 \mathrm{~g}$ of anhydrous glucose dissolved in water [16]. Glycosylated hemoglobin A1C levels were also measured.

For estimation of SOD activity, centrifugation of the blood samples was done at $1000 \mathrm{~g}$ for $10 \mathrm{~min}$, the serum was frozen and stored at $-80{ }^{\circ} \mathrm{C}$ until the time of analysis. SOD activity was based on the ability of the enzyme to inhibit the reduction of nitro blue tetrazolium dye mediated by phenazine methosulphate. The purified SOD inhibits the initial rate of reduction of (O2 to $\mathrm{O} 2-)$ mediated by the activated phenazine methosulphate which then reduces the nitro blue tetrazolium. The percentage of inhibition was then calculated and compared to the standard of $0.5 \mu \mathrm{g}$ of the enzyme that produced inhibition of $80 \%$ (activity $=3.000$ units $/ \mathrm{mg}$ protein). The SOD activity was finally expressed as units of enzymatic activity per milligram of protein contained in the samples (U/mg protein) [20].

Malondialdehyde (MDA) concentrations were measured in $\mu \mathrm{mol} /$ liter using the derivatization MDA with thiobarbituric acid (TBA) based on spectrophotometric determination of pink fluorescent MDA-TBA complex produced after reaction with 2-thiobarbituric acid at high temperature and low $\mathrm{pH}[21,22]$. The assay kits for MDA and SOD were products of Cell Biolabs Inc., San Diego, USA.

Patients were divided into two groups (A and B) using a computer-based software Open Epi version 3.21. Patients in group A received metformin $500 \mathrm{mg}$ three times daily [5] with meals for 6 months (Metfor ${ }^{\ominus} 500$ mg, metformin hydrochloride tablets; TABUK Pharmaceutical, KSA). Patients in group B received a combination of metformin $500 \mathrm{mg}$ three times daily with meals (Metfor $500 \mathrm{mg}$, metformin hydrochloride tablets; TABUK Pharmaceutical, KSA) and thymoquinone (TQ) in the form of black cumin oil (Cumin Mar black cumin oil $500 \mathrm{mg}$ soft gel capsules, MARNYS, Spain) three times daily before meals for 6 months.

Patients were instructed not to receive any non-study drug during the study period, to increase their physical activity by performing aerobic physical exercise (moderate level for $2 \mathrm{~h}$ and 30 min weekly or vigorous level for $1 \mathrm{~h}$ and $15 \mathrm{~min}$ weekly) divided over at least 3 days of the week, and to consume a low caloric diet.

All patients were advised to attend for follow-up after 3 and 6 months from the beginning of the study for evaluation of their BMI, waist circumference, hip circumference, and waist:hip ratio and to withdraw a blood sample for OGTT, A1C, SOD activity, and MDA concentration. Patients were also asked about their menstrual cycle pattern.

The primary study outcomes were as follows: the resumption of regular menstrual cycles, weight reduction as detected by decreased BMI, change of body fat distribution as proved by reduced waist:hip ratio, improvement of the glycemic control as documented by normalization of OGTT and $\mathrm{A} 1 \mathrm{C}$, and regaining the normal oxidative balance as evidenced by decreased MDA concentration and increased SOD activity. 


\section{Sample size calculation}

This was carried out using a computer software G Power $^{\oplus}$ version 3.1.5 (Franz Faul, Universität Kiel, Germany).

\section{Results}

During the study period, 343 overweight and obese PCOS patients visited the obstetrics and gynecology clinic, complaining of oligomenorrhea or amenorrhea with or without hirsutism. Screening for eligibility was done and 274 patients were found to fit the inclusion criteria. The study protocol, the involved intervention, and the follow-up process were fully explained to all patients. Two hundred fifty-three patients were willing to participate in the study and signed an informed consent for participation. Those 253 patients were simply randomized into 2 groups: 126 patients in group A (metformin $500 \mathrm{mg}$ three times daily for 6 months) and 127 patients in group B (metformin $500 \mathrm{mg}$ plus thymoquinone $500 \mathrm{mg}$, three times daily for 6 months). Patients who got pregnant and those who dropped out from follow-up during the study period were excluded from the statistics and results (22 patients from group A and 24 patients from group B). Finally, statistical analysis was done for 207 patients (104 patients from group A and 103 patients from group B). The study flowchart is shown in Fig. 1.
As regard the demographic and clinical parameters (i.e., age, marital status, oligomenorrhea or amenorrhea, BMI, waist:hip ratio, number of prediabetic patients), there were no statistically significant differences $(P>$ 0.05 ) between the 2 studied groups as shown in Table 1. Regarding the oxidative stress markers (serum SOD activity and MDA concentrations), there was no statistically significant difference $(P>0.05)$ between the 2 studied groups. The mean value for serum SOD activity in group A was $44.36 \pm 13.26 \mathrm{U} / \mathrm{mg}$ protein compared to $44.25 \pm 12.37 \mathrm{U} / \mathrm{mg}$ protein in group $\mathrm{B}$. The mean value for MDA concentrations for group A was $0.31 \pm$ $0.03 \mu \mathrm{mol} / \mathrm{l}$ compared to $0.32 \pm 0.04 \mu \mathrm{mol} / \mathrm{l}$ for group $\mathrm{B}$ (Table 1).

Regarding the number of patients with oligomenorrhea or amenorrhea, there was a highly significant difference $(P=0.0008)$ after 6 months of treatment in group A as 43 patients $(41.4 \%)$ achieved regular menstrual cycles. In group $\mathrm{B}$, there was a highly significant difference $(P=$ $0.00)$ after 6 months of treatment with 64 patients (62.2\%) achieving regular menstrual cycles. Comparing both groups after 6 months of treatment, there was a statistically significant $(P=0.031)$ difference as shown in Table 2.

In group $B$, there was a highly significant difference in the body mass index $(P=0.00)$ after 6 months of treatment. In group $\mathrm{A}$, there was no significant difference $(P$ $=0.18)$ in the BMI at the end of study period.

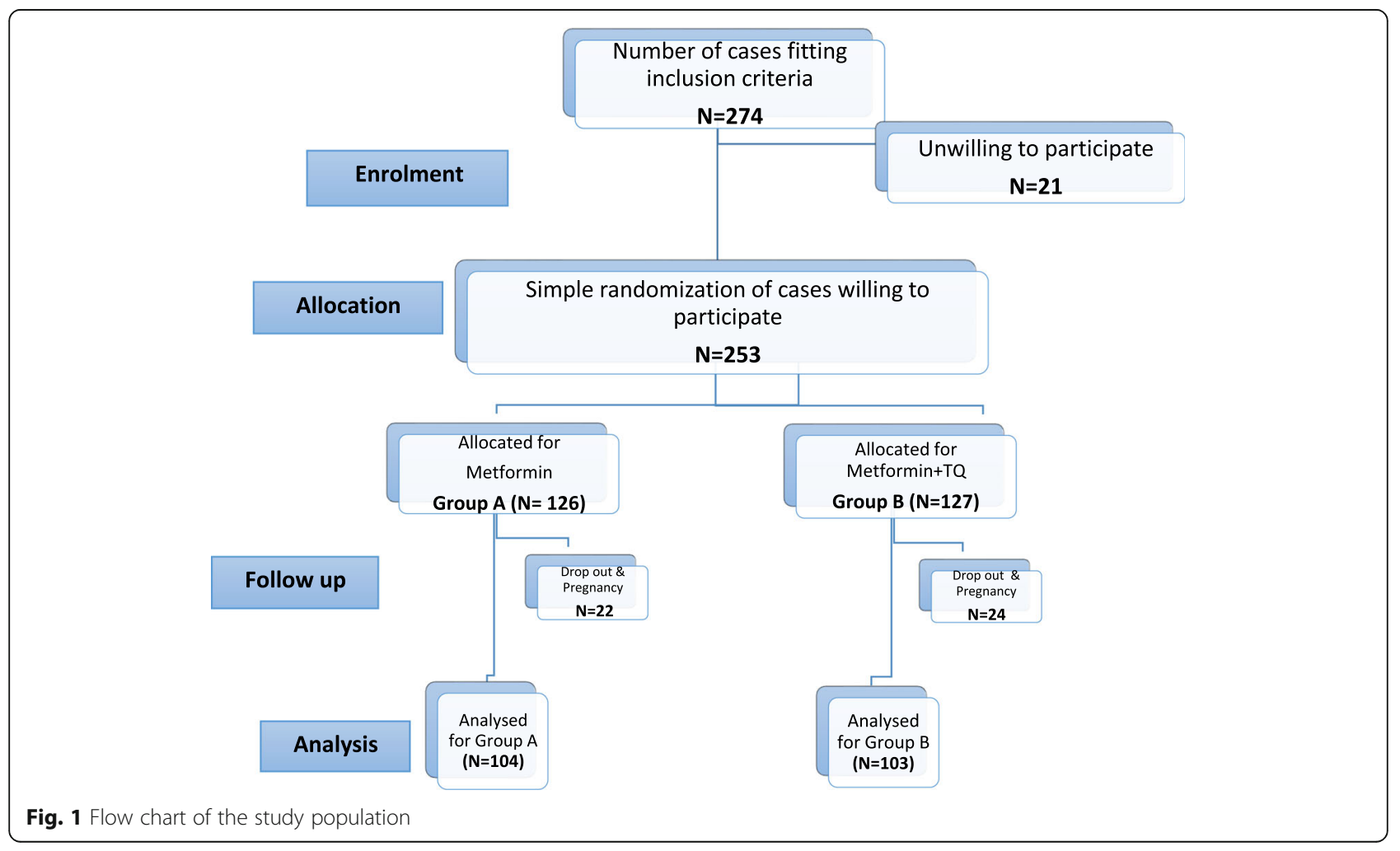


Table 1 Demographic and clinical data of the study population

\begin{tabular}{|c|c|c|c|}
\hline & $\begin{array}{l}\text { Group A } \\
N=104\end{array}$ & $\begin{array}{l}\text { Group B } \\
N=103\end{array}$ & $P$ \\
\hline Age & $24.59 \pm 5.3$ & $24.48 \pm 4.9$ & 0.88 \\
\hline \multicolumn{4}{|l|}{ Marital status } \\
\hline Married & $73(70.2 \%)$ & $71(68.9 \%)$ & 0.8 \\
\hline Single & $31(29.8 \%)$ & $32(31.1 \%)$ & 4 \\
\hline Oligomenorrhea or amenorrhea & $104(100 \%)$ & $103(100 \%)$ & 1.0 \\
\hline BMI $\left(\mathrm{kg} / \mathrm{m}^{2}\right)$ & $29.65 \pm 4.39$ & $29.71 \pm 4.13$ & 0.94 \\
\hline Waist circumference $(\mathrm{cm})$ & $98.5 \pm 10$ & $98.3 \pm 9$ & 0.87 \\
\hline Hip circumference $(\mathrm{cm})$ & $120.4 \pm 11$ & $120.2 \pm 10$ & 0.89 \\
\hline Waist:hip ratio & $0.86 \pm 0.05$ & $0.85 \pm 0.04$ & 0.67 \\
\hline Number of prediabetes cases & $35(33.6 \%)$ & $34(33.0 \%)$ & 0.95 \\
\hline Serum SOD activity (U/mg protein) & $44.36 \pm 14.26$ & $44.25 \pm 19.37$ & 0.96 \\
\hline MDA concentrations $(\mu \mathrm{mol} / \mathrm{l})$ & $0.31 \pm 0.03$ & $0.32 \pm 0.04$ & 0.47 \\
\hline
\end{tabular}

Comparing both groups at the end of study period, there was a highly significant difference $(P=0.00)$ in the BMI as shown in Table 3. Regarding the waist:hip ratio, there was a highly significant difference $(P=0.0001)$ at the end of study period in group $B$. While in group $A$, there was no significant difference $(P=0.36)$ after 6 months of treatment. Comparing both groups at the end of study period, there was a highly significant difference $(P=$ 0.00) in the WHR as shown in Table 3.

In group $\mathrm{A}$, there was a statistically significant decrease $(P=0.023)$ in the number of prediabetic patients after 6 months of treatment. Also, in group B, there was a significant decrease $(P=0.017)$ after 6 months of treatment. Comparing both groups at the end of study period, there was no statistically significant difference $(P$ $=0.89$ ) as shown in Table 4 .

As regard the serum SOD activity, there was a highly significant increase $(P=0.00)$ after 6 months of treatment in group A. Also, in group B, there was a highly significant increase $(P=0.00)$ in the mean values after 6 months of treatment. Comparing both groups at the end of study period, there was a highly significant difference $(P=0.00)$ as shown in Table 5 . Regarding the MDA concentrations, there was a highly significant decrease $(P$ $=0.0004$ ) after 6 months of treatment in group A. Also, in group $\mathrm{B}$, there was a highly significant decrease $(P=$
0.00) in the mean values after 6 months of treatment. Comparing both groups at the end of study period, there was a significant difference $(P=0.03)$ as shown in Table 5 .

\section{Discussion}

Previous studies in literature demonstrated the role of Nigella sativa oil supplementation in women with PCOS. Naeimi et al. conducted the first double-blinded study of the effect of $\mathrm{N}$. sativa on the menstrual pattern in PCOS patients. The intervention group of patients received two soft gelatin capsules of $500 \mathrm{mg}$ N. sativa oil $(1000 \mathrm{mg})$ while the placebo group received capsules of sunflower oil at night. The menstrual interval was significantly shorter after 16 weeks in the intervention group (45 days) compared to the placebo group (86 days), and hence the frequency of menstrual cycles (cyclicity) in the intervention group was significantly higher. But they reported that there were no statistically significant differences regarding the body mass index, waist:hip ratio, and oral glucose tolerance test [23].

Naeimi and his colleagues had previously carried out a study in 2018 for the effect of N. sativa on oligoamenorrhea in PCOS patients but differently there was no placebo group, the patients received only half the previous dose of the drug and in the form of powder-

Table 2 Comparison between the two studied groups in number of patients with oligomenorrhea or amenorrhea

\begin{tabular}{|c|c|c|c|c|c|c|}
\hline $\begin{array}{l}\text { Number of patients with oligomenorrhea or } \\
\text { amenorrhea }\end{array}$ & $\begin{array}{l}\text { At the beginning of the } \\
\text { study }\end{array}$ & $\begin{array}{l}\text { After } 3 \\
\text { months }\end{array}$ & $\begin{array}{l}\text { After } 6 \\
\text { months }\end{array}$ & $P 1$ & $P 2$ & P3 \\
\hline Group A & $104(100 \%)$ & 93 (89.4\%) & 61 (58.6\%) & 0.42 & $0.0008^{* *}$ & $0.01^{*}$ \\
\hline Group B & 103 (100\%) & 91 (88.3\%) & $39(37.8 \%)$ & 0.38 & $0.00^{* *}$ & $0.00^{* *}$ \\
\hline$P$ & ---- & 0.93 & $0.031 *$ & & & \\
\hline
\end{tabular}

*Statistically significant

**Highly significant $(\leq 0.001)$

$P 1$, beginning of the study compared to after 3 months; $P ; 2$, beginning of the study compared to after 6 months; $P 3$, after 3 months compared to after 6 months 
Table 3 Comparison of the body mass index and waist:hip ratio between the two studied groups

\begin{tabular}{|c|c|c|c|c|c|c|c|}
\hline & & At the beginning of the study & After 3 months & After 6 months & $P 1$ & $P 2$ & P3 \\
\hline \multirow[t]{3}{*}{ BMI $\left(\mathrm{kg} / \mathrm{m}^{2}\right)$} & Group A & $29.65 \pm 4.39$ & $28.75 \pm 3.98$ & $28.93 \pm 3.21$ & 0.14 & 0.18 & 0.71 \\
\hline & Group B & $29.71 \pm 4.13$ & $27.88 \pm 4.01$ & $24.32 \pm 2.28$ & $0.002^{*}$ & $0.00^{* *}$ & $0.001 * *$ \\
\hline & $P$ & 0.93 & 0.12 & $0.00^{* *}$ & & & \\
\hline \multirow[t]{3}{*}{ Waist:hip ratio } & Group A & $0.86 \pm 0.05$ & $0.85 \pm 0.04$ & $0.84 \pm 0.04$ & 0.58 & 0.36 & 0.51 \\
\hline & Group B & $0.85 \pm 0.04$ & $0.82 \pm 0.08$ & $0.75 \pm 0.04$ & 0.24 & $0.0001 * *$ & $0.007^{*}$ \\
\hline & $P$ & 0.96 & 0.86 & $0.00 * *$ & & & \\
\hline
\end{tabular}

*Statistically significant

**Highly significant $(\leq 0.001)$

$P 1$, beginning of the study compared to after 3 months; $P 2$, beginning of the study compared to after 6 months; $P 3$, after 3 months compared to after 6 months

contained capsules. They reported a significant improvement in the interval between menstrual cycles and the insulin resistance parameters after 4 months of consuming N. sativa [24]. Naeimi et al. postulated that the reduced effectiveness of $\mathrm{N}$. sativa oil capsules on the glycemic control and insulin resistance could be attributed to the loss of some structural components from the oil form while being still preserved in the powdercontained capsules [23].

One of the possible mechanisms by which thymoquinone is decreasing the menstrual intervals, is the phytoestrogenic effect [25]. Phytoestrogens were found in many plants and represent weak estrogenic compounds that react with estrogen receptors [26-28]. Parhizkar et al. compared the effect of N. sativa versus conjugated estrogen on the vaginal epithelium of menopausal rats and reported that the methanol extract of $\mathrm{N}$. sativa exerted significant estrogenic effects [29].

Resumption of menstrual cyclicity has been also attributed to the anti-inflammatory and antioxidant activity of TQ [30]. Oxidative stress refers to the imbalance between reactive oxygen species and the biologic antioxidant capacity of the body [31]. Recent studies had much implicated oxidative stress in the pathogenesis of PCOS and reported significant improvement of symptoms when using antioxidants [32].

Another postulated mechanism is the effect of TQ on insulin resistance and glucose metabolism [33]. Administration of $\mathrm{N}$. sativa (2-3 g daily) for 3 months in patients with type 2 diabetes mellitus can improve the glycemic control and insulin resistance, possibly because of the antioxidant activity of TQ that preserves and enhances the performance of the pancreatic beta cells and eventually improves insulin secretion and decreases insulin resistance [23]. Hyperinsulinemia decreases the hepatic production of sex hormone binding globulin (SHBG) and increases the levels of free serum androgens which eventually prevents the growth of ovarian follicles. Thus, any remarkable decrease in serum insulin level will improve the menstrual cyclicity with resumption of normal ovulation [34]. Nafiu et al. reported that $\mathrm{N}$. sativa oil can induce activation of insulin receptors and hence improves the tissue sensitivity to insulin with an associated increase in peripheral glucose utilization in rats [35].

Both obese and lean PCOS patients suffer from a degree of insulin resistance. The included patients in the current study were either overweight or obese, and thus they suffered from their own burden of obesity-related insulin resistance. Also, an intrinsic insulin resistance has been implicated in the disorder. Metformin acts as an insulin sensitizing agent that enhances the insulin sensitivity and thus stops the stimulant effect of hyperinsulinemia on the androgen secreting theca cells in response to high serum luteinizing hormone (LH) levels [15]. Moreover, the significant reduction of body weight in patients who received a combination of thymoquinone and metformin, may have eventually led to an increase of SHBG and subsequently decrease of free testosterone levels which contributed to the resumption of regular menstrual cycles.

Metformin has been proved as an effective drug in restoring regular menstrual cycles in PCOS patients. Talaat and Ammar reported that after 6 months of

Table 4 Comparison of the number of prediabetic patients between the two studied groups

\begin{tabular}{|c|c|c|c|c|c|c|}
\hline Number of prediabetes patients & At the beginning of the study & After 3 months & After 6 months & $P 1$ & $P 2$ & P3 \\
\hline Group A $(N=104)$ & 35 (33.6\%) & $27(25.9 \%)$ & $18(17.3 \%)$ & 0.29 & $0.023^{*}$ & 0.21 \\
\hline Group $B(N=103)$ & $34(33.0 \%)$ & $26(25.2 \%)$ & $17(16.5 \%)$ & 0.26 & $0.017^{*}$ & 0.16 \\
\hline$P$ & ----- & 0.92 & 0.89 & & & \\
\hline
\end{tabular}

*Statistically significant

$P 1$, beginning of the study compared to after 3 months; $P 2$, beginning of the study compared to after 6 months; $P 3$, after 3 months compared to after 6 months 
Table 5 Comparison of the serum SOD activity and MDA between the two studied groups

\begin{tabular}{llllllll}
\hline & & At the beginning of the study & After 3 months & After 6 months & $P 1$ & $P 2$ & $P 3$ \\
\hline Serum SOD activity $(U / \mathrm{mg}$ protein) & Group A & $44.36 \pm 14.26$ & $52.31 \pm 14.2$ & $60.27 \pm 12.22$ & $0.005^{*}$ & $0.00^{* *}$ & $0.00^{* *}$ \\
& Group B & $44.25 \pm 19.37$ & $60.16 \pm 13.8$ & $76.08 \pm 8.38$ & $0.00^{* *}$ & $0.00^{* *}$ & $0.00^{* *}$ \\
& $P$ & 0.98 & $0.00^{* *}$ & $0.00^{* *}$ & & \\
MDA $(\mu \mathrm{mol} / \mathrm{l})$ & Group A & $0.31 \pm 0.03$ & $0.29 \pm 0.03$ & $0.26 \pm 0.02$ & 0.15 & $0.0004^{* *}$ & $0.03^{*}$ \\
& Group B & $0.32 \pm 0.04$ & $0.26 \pm 0.02$ & $0.23 \pm 0.03$ & $0.0002^{* *}$ & $0.00^{* *}$ & $0.03^{*}$ \\
& $P$ & 0.52 & $0.03^{*}$ & $0.03^{*}$ & & &
\end{tabular}

*Statistically significant

**Highly significant $(\leq 0.001)$

$P 1$, beginning of the study compared to after 3 months; $P 2$, beginning of the study compared to after 6 months; $P 3$, after 3 months compared to after 6 months

treatment with metformin $500 \mathrm{mg}$ three times daily, $41.6 \%$ of patients achieved regular menstrual cycles [15]. Other studies in literature reported that a daily dose of metformin, ranging from 850 to $2550 \mathrm{mg}$, can restore ovulatory cycles within 5 months [36].

The majority of obese and $70 \%$ of lean PCOS patients have an abnormal (android) fat distribution. Hyperinsulinemia is mainly a result of increased visceral fat and it is recommended, as per the UK guidelines, to achieve successful weight reduction till BMI becomes less than 30 $\mathrm{kg} / \mathrm{m}^{2}$ before either administration of metformin or commencing induction of ovulation in obese PCOS patients [4]. Morbidly obese patients with BMI of $\geq 35 \mathrm{~kg} /$ $\mathrm{m}^{2}$ were not included in the current study. Metformin is not considered as a weight reducing drug and it is a common problem to fail in regaining normal ovulation in morbidly obese patients [15]. We did not find any significant decrease in neither the BMI nor the waist:hip ratio in the metformin only group $(P=0.18$ and 0.36 respectively).

Metformin is well-known for its effectiveness in increasing the sensitivity of insulin in the peripheral tissues; reducing hepatic gluconeogenesis, insulin resistance, and fasting serum insulin levels; and in activating the absorption of peripheral blood glucose through an adenosine monophosphate activated protein kinase (AMPK) [37]. Hyperglycemia induces an oxidative stress with subsequent increase of reactive oxygen species (ROS). Metformin can exert an antioxidant activity by activating the AMPK and inducing the endogenous antioxidant system with subsequent increase in superoxide dismutase (SOD) activity and reduction of malondialdehyde (MDA) concentrations [38]. The insulin sensitizing effect of metformin will eventually break the vicious circle of PCOS [15]. This explains the resumption of regular menstrual cycles in $41.4 \%$ of patients, normalization of glycemic status in $48.6 \%$ of patients, and the regaining of normal oxidative balance in the metformin only group.

Moustafa et al. studied the administration of N. sativa monotherapy in newly diagnosed patients with type 2
DM for 3 months. Their patients were assigned to either metformin $2000 \mathrm{mg}$ per day or Nigella sativa $450 \mathrm{mg}$ three times daily $(1350 \mathrm{mg} /$ day). There was a significant improvement in fasting plasma glucose (FPG) levels, BMI, and waist circumference at the end of the study period in both groups. Only the metformin group showed a significant improvement in the $2 \mathrm{~h}$ postprandial glucose and A1C. Nigella sativa was inferior to metformin in terms of lowering FPG, $2 \mathrm{~h}$ postprandial glucose, and $\mathrm{A} 1 \mathrm{C}$. However, NS was comparable to metformin in lowering the body weight, waist circumference, and BMI significantly and was well tolerated with no side effects [39].

As far as we know, this is the first study to investigate the conferred advantage of adding the active component of Nigella sativa oil (thymoquinone) to metformin in controlling PCOS-related disorders when compared with metformin alone.

Nigella sativa oil has a very low degree of toxicity and it appears that thymoquinone can kill tumor cells efficiently without any cytotoxic effect on normal cells. Thus, nowadays, thymoquinone as a phytochemical has successfully attracted the scientific research, as a promising alternative to the conventional drugs, for the fact that it has a high biological activity and remarkably low systemic toxicity. The role of plant-derived antioxidants has recently gained much popularity as dietary supplements due to their cheap cost, easy availability, religious and cultural background, safety, and efficacy [6]. The choice of thymoquinone in the present study was due to its availability in the Saudi market, relatively reasonable price, safety, and efficacy.

\section{Limitations of this study}

The studied drugs (metformin and black cumin oil capsules) were unfortunately non-covered items by medical insurance in KSA. So, the included patients had to pay in cash. Also, patients had to return for regular follow-up visits for their laboratory investigations. 


\section{Conclusions}

Black cumin oil supplementation, in the form of $500 \mathrm{mg}$ soft gel capsules three times daily for 6 months, constitutes a beneficial added value to metformin in ameliorating PCOS-related disorders with resumption of menstrual regularity, weight reduction, change of body fat distribution, and regaining oxidative balance. However, further studies are warranted to study thymoquinone as a single agent when compared with metformin or with placebo.

\begin{abstract}
Abbreviations
AMPK: Adenosine monophosphate activated protein kinase; BMI: Body mass index; CAT: Catalase; DM: Diabetes mellitus; FPG: Fasting plasma glucose; GSH: Glutathione; GSH-Px: Glutathione peroxidase; GST: Glutathione-Stransferase; HC: Hip circumference; IFG: Impaired fasting glucose; IGT: Impaired glucose tolerance; LH: Luteinizing hormone; MDA: Malondialdehyde; NS: Nigella sativa; OGTT: Oral glucose tolerance test; PCOS: Polycystic ovary syndrome; SHBG: Sex hormone binding globulin; SOD: Superoxide dismutase; ROS: Reactive oxygen species;

TBA: Thiobarbituric acid; TQ: Thymoquinone; TVS: Transvaginal ultrasound; WC: Waist circumference; WHO: World Health Organization; WHR: Waist:hip ratio
\end{abstract}

\section{Acknowledgements}

The two authors would like to thank all the staff members of the Departments of Obstetrics and Gynecology and Clinical Pathology, of the Saudi German Hospital, Madinah, as well as all included patients for their valuable participation to this work.

\section{Authors' contributions}

IMMA: Conception and design of study, acquisition of data, and manuscript revision. MAAS: Analysis of data, manuscript drafting, and manuscript revision. All authors have read and approved the manuscript.

\section{Funding}

Not applicable

\section{Availability of data and materials}

The data that support the findings of this study are available from the corresponding author (Islam Mohamed Magdi Ammar) upon reasonable request.

\section{Declarations}

\section{Ethics approval and consent to participate}

The Human Research Ethics Committee of the Saudi German Hospital Madinah has approved the study prospectively and full ethical approval has been granted. Trial registration: ClinicalTrials.gov Identifier: NCT04852510 (retrospectively registered on April 9, 2021).

Written informed consent was obtained from all patients before participating in the study.

\section{Consent for publication}

Not applicable

\section{Competing interests}

The authors declare that there are no actual or potential competing interests with respect to research, authorship, and/or publication of this article.

Received: 25 April 2021 Accepted: 15 August 2021

Published online: 23 August 2021

\section{References}

1. El Refaeey A, Selem A, Badawy A (2014) Combined coenzyme Q10 and clomiphene citrate for ovulation induction in clomiphene-citrate-resistant polycystic ovary syndrome. Reprod Biomed Online. 29(1):119-124. https:// doi.org/10.1016/j.rbmo.2014.03.011
2. Shokrpour M, et al. Effects of coenzyme Q10 supplementation on antimullerian hormone levels in patients with polycystic ovarian syndrome. Ann Med Health Sci Res. 2019;9:440-2.

3. Murri M, Luque-Ramírez M, Insenser M, Ojeda-Ojeda M, Escobar-Morreale HF (2013) Circulating markers of oxidative stress and polycystic ovary syndrome (PCOS): a systematic review and meta-analysis. Hum Reprod Update. 19(3): 268-288. https://doi.org/10.1093/humupd/dms059

4. Della Corte L, Foreste V, Barra F, Gustavino C, Alessandri F, Centurioni MG, Ferrero S, Bifulco G, Giampaolino P (2020) Current and experimental drug therapy for the treatment of polycystic ovarian syndrome. Expert Opin Investig Drugs. 29(8):819-830. https://doi.org/10.1080/13543784.2020.1781815

5. Facchinetti F, Orru B, Grandi G, Unfer V (2019) Short-term effects of metformin and myo-inositol in women with polycystic ovarian syndrome (PCOS): a meta-analysis of randomized clinical trials. Gynecol Endocrinol. 35(3):198-206. https://doi.org/10.1080/09513590.2018.1540578

6. Darakhshan S, Pour AB, Colagar AH, Sisakhtnezhad S (2015) Thymoquinone and its therapeutic potentials. Pharmacol Res. 95:138-158

7. El-Dakhakhny M (1963) Studies on the chemical constitution of Egyptian Nigella sativa L. Seeds. II1 the essential oil. Planta Med. 11(04):465-470

8. Goyal SN, Prajapati CP, Gore PR, Patil CR, Mahajan UB, Sharma C, Talla SP, Ojha SK (2017) Therapeutic potential and pharmaceutical development of thymoquinone: a multitargeted molecule of natural origin. Front Pharmacol. 8:656. https://doi.org/10.3389/fphar.2017.00656

9. Salem ML (2005) Immunomodulatory and therapeutic properties of the Nigella sativa L. seed. Int Immunopharmacol. 5(13-14):1749-1770. https:// doi.org/10.1016/j.intimp.2005.06.008

10. Salmani JM, Asghar S, Lv H, Zhou J (2014) Aqueous solubility and degradation kinetics of the phytochemical anticancer thymoquinone; probing the effects of solvents, pH and light. Molecules. 19(5):5925-5939. https://doi.org/10.3390/molecules19055925

11. Amin B, Hosseinzadeh $H$ (2016) Black cumin (Nigella sativa) and its active constituent, thymoquinone: an overview on the analgesic and antiinflammatory effects. Planta Med. 82(1-2):8-16

12. Bolton JL, Dunlap T (2017) Formation and biological targets of quinones: cytotoxic versus cytoprotective effects. Chem Res Toxicol. 30(1):13-37. https://doi.org/10.1021/acs.chemrestox.6b00256

13. Kooti W, Farokhipour M, Asadzadeh Z, Ashtary-Larky D, Asadi-Samani M (2016) The role of medicinal plants in the treatment of diabetes: a systematic review. Electron Physician. 8(1):1832-1842. https://doi.org/10.1 9082/1832

14. Kaatabi H, Bamosa AO, Badar A, Al-Elq A, Abou-Hozaifa B, Lebda F, AlKhadra A, Al-Almaie S (2015) Nigella sativa improves glycemic control and ameliorates oxidative stress in patients with type 2 diabetes mellitus: placebo controlled participant blinded clinical trial. PloS One. 10(2): e0113486. https://doi.org/10.1371/journal.pone.0113486

15. Talaat B, Ammar IM (2018) The added value of cinnamon to metformin in controlling symptoms of polycystic ovary syndrome, a randomized controlled trial. Middle East Fertil Soci J. 23(4):440-445. https://doi.org/10.1 016/j.mefs.2018.03.005

16. American Diabetes Association (2014) Diagnosis and classification of diabetes mellitus. Diabetes Care 37(Supplement 1):S81-\$90

17. Kilpatrick ES, Bloomgarden ZT, Zimmet PZ (2009) International expert committee report on the role of the A1C assay in the diagnosis of diabetes: response to the international expert committee. Diabetes Care 32(12):e159

18. Chang Y, Guo X, Chen Y, Guo L, Li Z, Yu S, Yang H, Sun Y (2015) A body shape index and body roundness index: two new body indices to identify diabetes mellitus among rural populations in northeast China. BMC Public health. 15(1):794. https://doi.org/10.1186/s12889-015-2150-2

19. World Health Organization. Waist circumference and waist-hip ratio: report of a WHO expert consultation, Geneva, 8-11 December 2008.

20. Seleem AK, El Refaeey AA, Shaalan D, Sherbiny Y, Badawy A (2014) Superoxide dismutase in polycystic ovary syndrome patients undergoing intracytoplasmic sperm injection. J Assist Reprod Genet. 31(4):499-504. https://doi.org/10.1007/s10815-014-0190-7

21. Sathyapalan T, Shepherd J, Coady AM, Kilpatrick ES, Atkin SL (2012) Atorvastatin reduces malondialdehyde concentrations in patients with polycystic ovary syndrome. J Clin Endocrinol Metabol. 97(11):3951-3955. https://doi.org/10.1210/jc.2012-2279

22. Reitznerová A, Šuleková M, Nagy J, Marcinčák S, Semjon B, Čertík M, Klempová T (2017) Lipid peroxidation process in meat and meat products: a 
comparison study of malondialdehyde determination between modified 2Thiobarbituric acid spectrophotometric method and reverse-phase highperformance liquid chromatography. Molecules. 22(11):1988. https://doi. org/10.3390/molecules22111988

23. Naeimi SA, Hajimehdipoor H, Saber S (2020) Comparing the effect of Nigella sativa oil soft gel and placebo on oligomenorrhea, amenorrhea and laboratory characteristics in patients with polycystic ovarian syndrome, a randomized clinical trial. Res J Pharmacognosy. 7(1):49-59

24. Naeimi SA, Tansaz M, Sohrabvand F, Hajimehdipoor H, Nabimeybodi R, Saber S, Shakiba M, Rohani M (2018) Assessing the effect of processed Nigella sativa on oligomenorrhea and amenorrhea in patients with polycystic ovarian syndrome: a pilot study. Int J Pharm Sci Res. 9(11):47164722

25. Latiff LA, Dollah MA, Hanachi P, Rahman SA (2011) A randomized control trial on the effect of black seeds (Nigella sativa) on climacteric symptoms and quality of life of perimenopausal women in Rawang, Selangor, Malaysia. Clin Biochem. 13(44):S20-S21

26. Naftolin F, Stanburg MG (2002) Phytostrogens: are they really estrogen mimics. Fertil Steril. 77(1):15-17. https://doi.org/10.1016/S0015-0282(01)02 006-4

27. Parhizkarsup S, Latiff LA, Rahman SA, Dollah MA (2011) Evaluation of estrogen-like activity of Nigella sativa in ovariectomized rats. Afr J Pharm Pharmacol. 5(8):1006-1011

28. Suzuki KM, Isohama Y, Maruyama H, Yamada Y, Narita Y, Ohta S, Araki Y, Miyata T, Mishima S (2008) Estrogenic activities of fatty acids and a sterol isolated from royal jelly. Evid Based Complement Altern Med. 1:5

29. Parhizkar S, Latiff LA, Rahman SA, Ibrahim R, Dollah A (2011) In vivo estrogenic activity of Nigella sativa different extracts using vaginal cornification assay. J Med Plants Res. 5(32):6939-6945

30. Leong XF, Rais Mustafa M, Jaarin K (2013) Nigella sativa and its protective role in oxidative stress and hypertension. Evid Based Complement Altern Med. 1:2013

31. Fathi FH (2020) Biomarkers of oxidative stress in polycystic ovary disorder Ann Coll Med Mosul. 41(2):112-116. https://doi.org/10.33899/mmed.2020.1 64152

32. Rostamtabar M, Esmaeilzadeh S, Tourani M, Rahmani A, Baee M, Shirafkan F, Saleki K, Mirzababayi SS, Ebrahimpour S, Nouri HR (2020) Pathophysiological roles of chronic low-grade inflammation mediators in polycystic ovary syndrome. J Cell Physiol. 236(2):824-838. https://doi.org/10.1002/jcp.29912

33. Mohtashami A, Entezari MH (2016) Effects of Nigella sativa supplementation on blood parameters and anthropometric indices in adults: a systematic review on clinical trials. J Res Med Sci. 21

34. Hashim HA (2016) Twenty years of ovulation induction with metformin for PCOS; what is the best available evidence? Reprod Biomed Online. 32(1):4453. https://doi.org/10.1016/j.rbmo.2015.09.015

35. Nafiu AB, Alimi S, Babalola A, Ogunlade AT, Muhammad FD, Abioye AR (2019) Anti-androgenic and insulin-sensitizing actions of Nigella sativa oil improve polycystic ovary and associated dyslipidemia and redox disturbances. J Complement Med Res. 10(4):186-199. https://doi.org/10.54 55/jcmr.20190613045154

36. Jazani AM, Azgomi HN, Azgomi AN, Azgomi RN (2019) A comprehensive review of clinical studies with herbal medicine on polycystic ovary syndrome (PCOS). DARU J Pharm Sci. 18:1-5

37. Hasanpour Dehkordi A, Abbaszadeh A, Mir S, Hasanvand A (2019) Metformin and its anti-inflammatory and anti-oxidative effects; new concepts. J Renal Inj Prev. 14:20-21

38. Chen X, Guo H, Qiu L, Zhang C, Deng Q, Leng Q (2020) Immunomodulatory and antiviral activity of metformin and its potential implications in treating coronavirus disease 2019 and lung injury. Front Immunol. 11:20-21

39. Moustafa HA, El Wakeel LM, Halawa MR, Sabri NA, El-Bahy AZ, Singab AN (2019) Effect of Nigella sativa oil versus metformin on glycemic control and biochemical parameters of newly diagnosed type 2 diabetes mellitus patients. Endocrine. 65(2):286-294. https://doi.org/10.1007/s12020-019-01 963-4

\section{Publisher's Note}

Springer Nature remains neutral with regard to jurisdictional claims in published maps and institutional affiliations.

\section{Submit your manuscript to a SpringerOpen ${ }^{\circ}$ journal and benefit from:}

- Convenient online submission

- Rigorous peer review

- Open access: articles freely available online

- High visibility within the field

- Retaining the copyright to your article

Submit your next manuscript at $\boldsymbol{\nabla}$ springeropen.com 